\title{
Profil izokinetickej sily extenzorov a flexorov kolena u mladých futbalových hráčov
}

\section{Isokinetic strength profile of knee flexors and extensors in young soccer players}

\author{
Tomáš Malý, František Zahálka, Lucia Malá, Jaroslav Teplan \\ Fakulta tělesné výchovy a sportu Univerzity Karlovy, Praha
}

\begin{abstract}
Abstrakt
Cielom štúdie bolo stanovit profil izokinetickej sily flexorov a extenzorov kolena u mladých futbalových hráčov pri koncentrickej svalovej kontrakcii. V prípade flexorov kolena bolo cielom zistit taktiež silu pri excentrickej kontrakcii a jej porovnanie s koncentrickou kontrakciou.

Sledovanou skupinou boli hráči futbalu kategorie U17 ( $n=19$, vek $=16,4 \pm 0,3$ rokov), ktorí hrajú najvyššiu domácu dorasteneckú ligovú sútaž. Parametre izokinetickej sily sme zistovali pomocou izokinetického dynamomentru Cybex Humac Norm v uhlových rýchlostiach 30, 60 a $120 \%$ s pri excentrickej kontrakcii a v rýchlostiach 60, 180, 240 a $300 \%$ pri koncentrickej kontrakcii.

Výsledky nepreukázali signifikantné rozdiely svalovej sily flexorov kolena pri excentrickej kontrakcii $v$ troch sledovaných rýchlostiach $(p>0,05)$. V prípade koncentrickej svalovej činnosti boli zistené signifikantné rozdiely $v$ produkcii svalovej sily $v$ závislosti od uhlovej rýchlosti pohybu u flexorov i extenzorov kolena, ked'so zvyšujúcou sa uhlovou rýchlostou došlo $k$ nižšej produkcii svalovej sily $(p<0,01)$. Pri excentrickej kontrakcii produkovali flexory vyššiu svalovú silu v porovnanís koncentrickou kontrakciou.

Výsledky štúdie by mohli pomôct' pri komparácii hodnôt iným autorom a pri zachovaní metodologických podmienok diagnostiky izokinetickej sily vytvorit východzí štandard pre posúdenie úrovne svalovej sily u vybraných svalových skupín u mladých futbalových hráčov.
\end{abstract}

\begin{abstract}
The aim of the study was to present isokinetic strength profile of knee flexors and extensors during concentric contraction in young soccer players. Particularly in knee flexors was evaluated also strength during eccentric contraction.

Research group was state from young soccer players U17 category ( $n=19$, age $=16,4 \pm 0,3$ years). All of them are the participant of highest junior soccer league.

Isokinetic strength was evaluated by isokinetic dynamometr Cybex Humac Norm in following angular velocities: 30, 60 and $120 \%$ in eccentric contraction and $60,180,240$ and $300 \%$ in concentric contraction.

The results did not revealed significant differences at three different speed levels of knee flexors' strength during eccentric contraction ( $p>0,05$ ). Regarding the concentric contraction we found significant differences for strength production depending on angular velocity for both knee extensors and flexors $(p<0,01)$. Knee flexors generated more strength during eccentric contraction compared to concentric contraction.

The strength profiles developed in the present study can assist in the establishment of baseline data in young soccer players or for comparison values with other researchers.
\end{abstract}

Klúčové slová: Izokinetická síla, koncentrická kontrakcia, excentrická kontrakcia, futbal Key words: Isokinetic strength, concentric contraction, eccentric contraction, soccer

Projekt bol podporený grantom GAČR P407/11/P784, MSM 0021620864 a SVV 2012-265603. 


\section{Úvod}

Pre vela športov je otázka vztahu sily k d’alším parametrom výkonu nejasná. Svalová sila je dôležitá nielen $\mathrm{z}$ hladiska športového výkonu, ale taktiež z pohladu preventívne zdravotného.

Testovanie svalovej sily dolných končatín má velký význam mimo iného i v kolektívnych športových hrách, kde svalové skupiny dolných končatín musia generovat i absorbovat’ vysokú úroveň silovej komponenty pri činnostiach ako akcelerácia, decelerácia, výskok, kopy, otočenie, zmena smeru a podobne.

Jednou z možností identifikácie svalovej sily je diagnostika silových parametrov a stanovenie silového profilu pomocou izokinetickej dynamometrie.

Používanie diagnostiky izokinetickej dynamometrie u elitných športovcov je v zahraničí využívané približne od roku 1960 (Wrigley \& Strauss, 2000). Testovanie svalovej sily v oblasti kolenného kíbu patrí medzi najčastejšie merané oblasti u populácie (Hoffman, 2006). Svensson a Drust (2005) považujú výsledky testovania pomocou izokinetickej dynamometrie u futbalových hráčov za dôležitú súčast hodnotenia telesnej zdatnosti úspešných hráčov.

Testovanie na izokinetickom dynamometri je akceptované a klinicky dôležité pre hodnotenie deficitu svalovej sily a silových dysbalancií u športovcov (Cometti et al., 2001). Morgan a Oberlander (2001) uvádzajú, že približne $75 \%$ zranení vo futbale sa vyskytujú na dolných končatinách. Ukazuje sa, že vysoká úroveň pomeru svalovej sily zadných stehenných svalov vzhladom k predným je dôležitým parametrom pri identifikácii zvýšeného rizika zranenia hráča (Friend \& Lloyd, 1992). Schopnost' produkovat vysokú úroveň svalovej sily zadnými stehennými svalmi pri excentrickej svalovej kontrakcii je dôležitou požiadavkou u hráčov športových hier (Carling, Reilly \& Wiliams, 2009). Maximálny silový moment je reliabilným indikátorom svalovej činnosti jak pri intaktnom, tak pri (po) zranení v oblasti kolenného kíbu. Zistené výstupy momentov svalovej sily príslušných svalových skupín v oblasti meraného kíbu podmieňujú mieru integrity a stability daného kĺbu (Hoffman, 2006). Unilaterálne porovnanie sily svalových skupín (agonista - antagonista) môže objavit potencionálne slabé miesta, ktoré zvyšujú mieru rizika zranenia športovca (Lin et al. 2010, Baratta et al. 1988, Knapik et al. 1991).

Fousekis et al. (2010) a Croisier et al. (2005) uvádzajú, že meranie izokinetickej sily by sa malo stat súčastou diagnostiky hráča pred prípravným obdobím s cielom zistenia nielen úrovne silových predpokladov, ale najmä silových asymetrií extenzorov a flexorov kolena. V domácej literatúre sa diagnostikou izokinetickej sily u mládeže zaoberali napr. Botek et al. (2010), Malý et al. (2010), Malý et al. (2011a). Avšak $\mathrm{v}$ uvedených štúdiách absentujú informácie o úrovni svalovej sily pri excentrickej kontrakcii, ktorá je dôležitou súčastou pohybového výkonu hráča.

Meranie izokinetickej sily poskytuje objektívny a jednoduchý prístup k hodnoteniu svalovej sily u hráčov. Napriek tomu ostáva vela nezodpovedaných otázok a kontroverzných výsledkov so silovým prejavom u mladých hráčov (Weir, 2000).

Cielom štúdie bolo stanovit’ profil izokinetickej sily flexorov a extenzorov kolena u mladých futbalových hráčov. V prípade flexorov kolena bolo cielom zistił taktiež silu pri excentrickej kontrakcii a jej porovnanie s koncentrickou kontrakciou.

\section{Metodika}

\section{Charakteristika výskumného súboru}

Sledovanou skupinou boli hráči futbalu kategorie U17 $(\mathrm{n}=19$, vek $=16,4 \pm 0,3$ rokov, telesná výška $=$ $175,7 \pm 8,5 \mathrm{~cm}$, telesná hmotnost’ = 66,2 $\pm 9,3 \mathrm{~kg}$ ), ktorí hrajú najvyššiu domácu dorasteneckú ligovú sútaž.

\section{Metódy získavania výskumných údajov}

Parametre izokinetickej sily sme sledovali pomocou izokinetického dynamomentru Cybex Humac Norm (Cybex NORM ^, Humac, CA, USA). Zistovali sme maximálny silový moment (PT) extenzorov a flexorov kolena dominantnej končatiny pri koncentrickej kontrakcii a v prípade flexorov kolena aj pri 
excentrickej kontrakcii. Meranie svalovej sily pri koncentrickej kontrakcii bolo realizované v uhlových rýchlostiach $60,180,240$ a $300 \%$ s. V prípade excentrickej kontrakcie boli flexory kolena diagnostikované v rýchlostiach $-30,-60$ a $-180 \%$ s. Postup testovania od najnižšej po najvyššiu rýchlost' pohybu bol štandardizovaný a odporučaný autormi Wilhite et al. (1992). Reliabilita PT a celkovej práce bola vyššia ako 0,90 pri troch testovacích rýchlostiach - 60, 120 a $180^{\circ} . \mathrm{s}^{-1}$ (Impelizzeri et al., 2008).

Pri testovaní sedel proband na sedadle dynamometra s fixovaným trupom a stehnom testovanej končatiny pomocou fixačných popruhov s cielom izolácie testovaných svalových skupín. Osa otáčania ramena dynamometra bola vizuálne nastavená s osou otáčania kolena pomocou laserového lúča. Pre každú z testovacích rýchlostí bola použitá príslušná gravitačná korekcia pre určenie maximálneho momentu sily, ktorá je súčastou testovacieho softwaru.

Pred testovaním proband absolvoval krátke rozcvičenie (rozbehanie 3 minúty, strečing individuálne, 3 série / 3 opakovania vertikálneho výskoku a 2 série / 10 opakovaní dynamických podrepov). Úlohou probanda bolo pri meraní vygenerovat maximálnu silu pri koncentrickej resp. excentrickej svalovej kontrakcii pri uvedených rýchlostiach pohybu. Pred každou rýchlostou mal proband 3 nácvičné opakovania. Počas testovania sa hráči držali pomocných postranných madiel dynamometra. Vizuálna spätná väzba a verbálna motivácia bola poskytnutá počas testovania všetkým hráčom. Medzi jednotlivými rýchlostami bola prestávka s pasívnym odpočinkom 60 s (Rahnama, Lees \& Bambaecichi, 2005), čo je dostatočný čas na obnovu energetických zdrojov ATP-CP (Parcel, et al., 2002).

\section{Metódy spracovania a vyhodnocovania výskumných údajov}

Výsledky izokinetickej sily prezentujeme v relatívnych hodnotách (podiel absolútnej hodnoty a telesnej hmotnosti hráča). Pre vyjadrenie miery polohy sme použili aritmetický priemer a pre vyjadrenie miery variability sme použili smerodajnú odchýlku. Taktiež uvádzame minimálnu a maximálnu hodnotu u sledovanej premennej. Pre grafické znázornenie sme použili spojnicový graf s vyjadrením miery variability u každej z testovaných rýchlostí. Porovnanie priemerov momentu svalovej sily sme realizovali pomocou analýzy rozptylu pre opakované merania (RM ANOVA). Pre zamietnutie nulovej hypotézy o rovnosti porovnávaných priemerov sily v sledovaných rýchlostiach sme zvolili riziko $\mathrm{p}<0,05$. V prípade signifikantných rozdielov sme použili Bonferroniho post-hoc test. Neštatistickú významnost' sme posudzovali pomocou koeficientu „Eta square - $\eta^{2 “}$, ktorý udáva percento vysvetleného rozptylu modelu pri zvolenom faktore (uhlová rýchlost’ pohybu). Štatistické spracovanie sme realizovali pomocou programu IBM SPSS ${ }^{\circledast} 19.0$.

\section{Výsledky}

Základné charakteristiky produkovanej sily v excentrickej kontrakcii (flexory kolena) a koncentrickej kontracii (flexory a extenzory kolena) sú uvedené v tabul'ke 1 a názornejšie prezentované v obrázku 1.

Analýza rozptylu pre opakované meranie nepreukázala signifikantné rozdiely svalovej sily flexorov kolena pri excentrickej kontrakcii $\mathrm{v}$ troch sledovaných rýchlostiach $\left(\mathrm{F}_{2,36}=1,78, \mathrm{p}=0,18, \eta^{2}=0,09\right)$. Naopak, v prípade koncentrickej svalovej činnosti boli zistené signifikantné rozdiely v produkcii svalovej sily v závislosti od uhlovej rýchlosti pohybu flexie kolena $\left(\mathrm{F}_{3,54}=147,3, \mathrm{p}=0,00, \eta^{2}=0,89\right)$. Faktor rýchlosti pohybu tak predstavuje viac ako $89 \%$ vysvetleného rozptylu. Na základe post hoc analýzy testov sme zistili signifikantné rozdiely v produkcii svalovej sily medzi každou zo sledovaných rýchlostí (60, 180, $240,300 \%$ s) ( $\mathrm{p}<0.01)$. So zvyšujúcou sa rýchlostou pohybu pri extenzii kolena v koncentrickej činnosti došlo $k$ signifikantnému zníženiu produkcie svalovej sily $\left(\mathrm{F}_{3,54}=322,6, \mathrm{p}=0,00, \eta^{2}=0,95\right)$. I v tomto prípade boli rozdiely v sile medzi každou zo sledovaných rýchlostí signifikantné $(\mathrm{p}<0.01)$. 
Tabulka 1 Úroveň izokinetickej sily (N.m/kg) flexorov a extenzorov kolena u mladých futbalových hráčov.

\begin{tabular}{|c|c|c|c|c|c|c|c|}
\hline \multicolumn{2}{|c|}{ Parametre merania } & Uhlová rych- & Rozsah & Minimum & Maximum & Aritmetický & Smerodajná \\
\hline \multirow{7}{*}{ 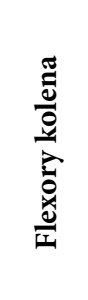 } & \multirow{3}{*}{$\begin{array}{l}\text { Excentrická } \\
\text { kontrakcia }\end{array}$} & -180 & 1,34 & 1,66 & 3,00 & 2,41 & 0,38 \\
\hline & & -60 & 1,36 & 1,56 & 2,92 & 2,30 & 0,41 \\
\hline & & -30 & 1,51 & 1,72 & 3,23 & 2,31 & 0,40 \\
\hline & \multirow{8}{*}{$\begin{array}{c}\text { Koncentrická } \\
\text { kontrakcia }\end{array}$} & 60 & 1,06 & 1,30 & 2,36 & 1,87 & 0,29 \\
\hline & & 180 & 0,76 & 0,91 & 1,67 & 1,33 & 0,24 \\
\hline & & 240 & 0,70 & 0,87 & 1,57 & 1,19 & 0,21 \\
\hline & & 300 & 0,88 & 0,72 & 1,60 & 1,08 & 0,21 \\
\hline \multirow{4}{*}{ 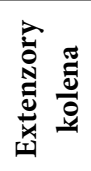 } & & 60 & 1,66 & 2,28 & 3,94 & 3,00 & 0,33 \\
\hline & & 180 & 1,10 & 1,57 & 2,67 & 2,12 & 0,30 \\
\hline & & 240 & 0,79 & 1,48 & 2,27 & 1,88 & 0,25 \\
\hline & & 300 & 0,88 & 1,17 & 2,05 & 1,66 & 0,24 \\
\hline
\end{tabular}

Obrázok 1 Grafické znázornenie profilu izokinetickej sily flexorov a extenzorov kolena pri koncentrickej a excentrickej kontrakcii.

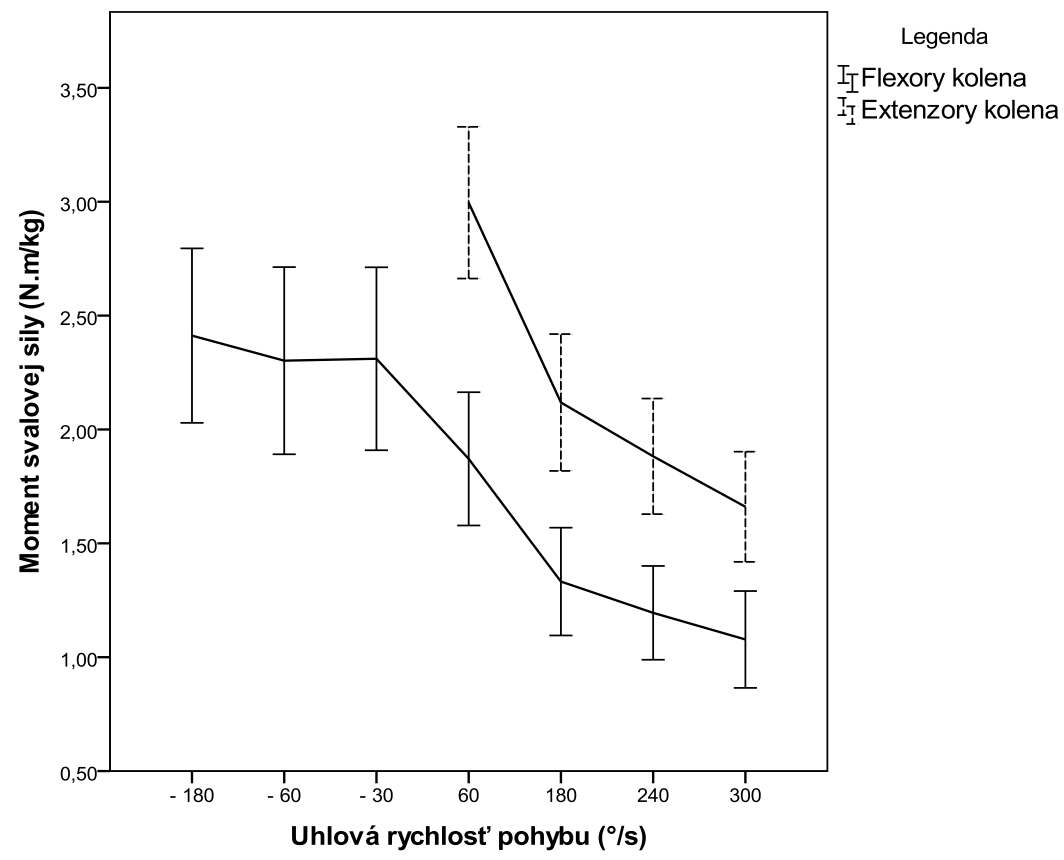

\section{Diskusia}

Nami sledovaný výber hráčov dosiahol nižšie relatívne hodnoty svalovej sily extenzorov kolena pri koncentrickej kontrakcii v porovnaní s reprezentačným výberom ČR kategórie U16 vo všetkých sledovaných rýchlostiach (Malý et al., 2011a). V prípade najnižšej rýchlosti $(60 \%$ s) bol rozdiel $4,8 \%$ a pri najvyššej rýchlosti $(300 \%$ s) bol rozdiel 4,6 \%. Obe skupiny dosiahli rovnaký priemerný výsledok úrovne svalovej sily flexorov kolena pri koncentrickej kontrakcii v najnižšej rýchlosti PT $=1,87 \mathrm{~N} \cdot \mathrm{m} / \mathrm{kg}$. Avšak pri najvyššej rýchlosti dosiahli mladší reprezentanti vyššiu silu v porovnaní so staršími hráčmi na klubovej úrovni o 3,6 \%. Lehance a kol. (2009) uvádzajú vyššiu hodnotu PT v rýchlosti 60 \% u elitných juniorských hráčov ( 1 . belgická liga) $(3,06 \pm 0,44 \mathrm{~N} . \mathrm{m} / \mathrm{kg})$. 
Niektoré zahraničné štúdie deklarujú vyššiu silu u profesionálnych hráčov v porovnaní s hráčmi nižšej výkonnostnej úrovne (Cometti et al., 2001, Gissis \& Papadopoulos, 2006). Naopak, Metaxas et al. (2009) nenašiel signifikantné rozdiely izokinetickej sily pri koncentrickej kontrakcii u rôzne výkonnostných hráčov Gréckej ligy (I až IV liga) pri troch odlišných rýchlostiach $\left(60,180\right.$ a $\left.300^{\circ} . \mathrm{s}^{-1}\right)$. V našej najvyššej seniorskej sútaži neboli taktiež zistené signifikantné rozdiely v úrovni svalovej sily extenzorov a flexorov kolena pri koncentrickej svalovej činnosti pri rôznych rýchlostiach (Malý et al., 2011b).

Kellis et al. (2001) uvádzajú u gréckych hráčov $(n=18$, vek=16,4 $\pm 0,2$ rokov, telesná výška $=175,7 \pm 6,0$ a telesná hmotnost' $=68,9 \pm 5,8 \mathrm{~kg}$ ) hodnoty svalovej sily extenzorov kolena pri rýchlosti $60 \%$ s,79 $\pm 0,35$ N.m/kg a pri rýchlosti $180 \% 2,07 \pm 0,25 \mathrm{~N} . \mathrm{m} / \mathrm{kg}$. Tieto hodnoty sú nižšie v porovnaní s našou skupinou hráčov. Taktiež hodnoty svalovej sily flexorov kolena boli pri nižšej rýchlosti $60 \% 1,75 \pm 0,25 \mathrm{~N} . \mathrm{m} / \mathrm{kg}$, ale pri vyššej rýchlosti 180 \% dosiahli gréckí hráči vyššiu priemernú hodnotu $(1,39 \pm 0,21 \mathrm{~N} . \mathrm{m} / \mathrm{kg})$ v porovnaní s našou skupinou $(1,33 \pm 0,24 \mathrm{~N} . \mathrm{m} / \mathrm{kg})$. Velký rozdiel sme zistili pri excentrickej kontrakcii flexorov kolena medzi nami sledovanou skupinou a gréckymi rovesníkmi, ked pri rýchlosti $60 \%$ dosiahli naši hráči hodnotu $2,30 \pm 0,41 \mathrm{~N} . \mathrm{m} / \mathrm{kg}$ a gréckí hráči $1,75 \pm 0,24 \mathrm{~N} . \mathrm{m} / \mathrm{kg}$. Tento rozdiel predstavuje 23,9

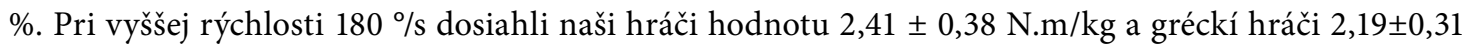
N.m/kg. Pri tejto rýchlosti je rozdiel medzi skupinami 9,1\%.

Hráči pri koncentrickej svalovej činnosti dosiahli signifikantne vyššie hodnoty pri nižších rýchlostiach v porovnaní s vyššími rýchlostami. Tieto výsledky sú v súlade s inými štúdiami (Gür et al., 1999, Dauty \& Potiron Jose, 2004, Kellis et al., 2001, Malý et al., 2010). So zvyšujúcou sa uhlovou rýchlostou došlo k zníženiu svalovej sily u extenzorov o 44,7 \% a flexorov 42,3 \%. (Rozdiel medzi PT dosiahnutým pri najnižšej rýchlosti $60^{\circ} . \mathrm{s}^{-1}$ a najvyššej rýchlosti $\left.300^{\circ} . \mathrm{s}^{-1}\right)$. Wong \& Wong (2009) uvádzajú u mladých čínskych reprezentantov kategórie U17 pokles PT extenzorov o 47 \% a PT flexorov kolena o 42 \% pri rovnakých uhlových rýchlostiach pohybu $\left(60^{\circ} \cdot \mathrm{s}^{-1} \mathrm{vs} .300^{\circ} \cdot \mathrm{s}^{-1}\right)$. Malý et al. (2011a) uvádzajú u hráčov reprezentačného výberu ČR kategórie U16 rozdiely 44,8 \% (extenzory kolena) resp. 40,3 \% (flexory kolena).

Zo zvyšujúcou sa rýchlostou pohybu úroveň svalovej sily extenzorov a flexorov kolena pri koncentrickej kontrakcii signifikantne klesala. Všeobecne platí, že pri koncentrickej kontrakcii sa so zvyšovaním rýchlosti pohybu znižuje sila, ktorú je sval schopný vyvinút. Tento vztah medzi silou a rýchlostou kontrakcie je známy ako Hillova krivka (Hill, 1938). Jedným z vysvetlení tohto vztahu je, že s rastúcou rýchlostou koncentrickej činnosti sa znižuje maximálny možný čas kontaktu medzi aktínom a myozínom (Huxleyho model), čím sa znižuje časová súčast' kontaktnej fázy na celkovom cykle. Krížové mostíky musia byt krátko po svojom spojení opät uvolnené, bez toho aby mali dostatok času na produkciu sily, čím klesá podiel spojených mostíkov vo svale a produkovaná sila je nižšia (Wirth \& Schmidtbleicher, 2007).

Naopak, pri excentrickej kontrakcii flexorov kolena sme so zvyšujúcou sa rýchlostou pohybu neznamenali signifikantné rozdiely.

Na základe rešerše literatúry, vlastných poznatkov a skúseností sa ukazujú nasledovné hlavné ciele $\mathrm{v}$ oblasti diagnostiky silových predpokladov: sledovanie silových indikátorov u športovca a jeho porovnanie s príslušnými normami, monitorovanie tréningového procesu v oblasti silovej prípravy, podmienenosṫ silových schopností vzhladom k výkonu v športovej disciplíne respektive k iným parametrom, identifikácia silových dysbalancií a určenie potenciálneho rizika zranenia športovca, monitorovanie procesu rehabilitácie po zranení.

Niektoré výsledky našej štúdie sú v súlade s výsledkami iných štúdií, avšak dalšie sú v protiklade. Jedna z možných príčin je nejasné označenie úrovne hráčov v zahraničných zdrojoch. Napríklad označenie „young elite soccer players“ sa vyskytuje pre rôzne druhy výkonnostnej úrovne hráča (hráč reprezentačného výberu, hráč najvyššej domácej sútaže príslušnej vekovej kategórie, hráč futbalovej akadémie a podobne). Ďalšia z možných príčin rozdielnych výsledkov môžu byt rozdiely v metodike zistovania výskumných údajov (spôsob rozcvičenia, testovanie pomocou izokinetickej dynamometrie s prekríženými pažami na hrudníku alebo s držaním madiel, poskytnutá verbálna motivácia a vizuálna spätná väzba a podobne). 


\section{Záver}

Štúdia prezentuje profil svalovej sily extenzorov a flexorov kolena u aktívnych futbalových hráčov najvyššej domácej dorasteneckej sútaže. Ako prvá štúdia v republike prezentuje výsledky svalovej sily flexorov kolena pri excentrickej svalovej kontrakcii. Silový profil nami sledovaných hráčov je v porovnaní s dostupnými údajmi zahraničných hráčov na porovnatel’nej respektive vyššej úrovni. So zvyšujúcou sa uhlovou rýchlostou pohybu dochádzalo pri koncentrickej kontrakcii k signifikantnému zníženiu úrovne izokinetickej sily extenzorov a flexorov kolena. Nami sledovaná uhlová rýchlost̉ nemala signifikantný vplyv na úroveň svalovej sily flexorov kolena. Pri excentrickej kontrakcii produkovali flexory vy̌̌šiu svalovú silu v porovnaní s koncentrickou kontrakciou. Výsledky štúdie by mohli pomôct pri komparácii hodnôt iným autorom a pri zachovaní metodologických podmienok diagnostiky izokinetickej sily vytvorit’ východzí štandard pre posúdenie úrovne svalovej sily u vybraných svalových skupín.

\section{LITERATÚRA}

BARATTA, R., SOLOMONOV, M., ZHOU, B.H., LETSON, D., CHUINARD, R. AND D‘AMBROSIA, R. (1988). Muscular coactivation: the role of the antagonist musculature in maintaining knee stability. Am. J. Sports. Med., 16, 113-122.

BOTEK, Z., GÁBA, A., LEHNERT, M., PŘIDALOVÁ, M., VAŘEKOVÁ, R., BOTEK, M. \& LANGER, F. (2010). Conditioning and body constitution of soccer players in category U19 before and after completing a preparatory period. Acta Universitatis Palackianae Olomucensis. Gymnica, 40, 47-54.

CARLING, C., REILLY, T. \& WILIAMS, M. (2009). Performance assessment for field sports. New York, NY: Routledge.

COMETTI, G., MAFFIULETTI, N.A., POUSSON, M., CHATARD, J.C. \& MAFFULLI, N. (2001). Isokinetic strength and anaerobic power of elite, sub-elite and amateur French soccer players. International Journal of Sports Medicine, 22, 45-51.

CROISIER, J.L., GANTEAUME, S., \& FERRET, J.M. (2005). Pre-season isokinetic intervention as a preventive strategy for hamstring injury in Professional soccer players [abstract]. British Journal of Sports Medicine, 39, 379.

DAUTY, M. \& POTIRON-JOSSE, M. (2004) Correlation and differences of performance between soccer players, professional, young players and amateurs, from the 10-meters sprint test and knee isokinetic assessment. Science \& Sports, 19, 75-79.

FOUSEKIS, K., TSEPIS, E. \& VAGENAS, G. (2010). Multivariate isokinetic strength asymmetries of the knee and ankle in professional soccer players. The journal of sports medicine and physical fitness, 50, 465-473.

FRIEND, T. \& LLOYD, G.J. (1992). An overview of commom soccer injuries. Management and prevention. Sports Medicine, 14, 269-275.

GISSIS, I. \& PAPADOPOULOS, C. (2006). Strength and speed characteristics of elite, subelite, and recreational young soccer players, Research in Sports Medicine, 14, 205-214.

GÜR, H., AKOVA, B., PÜNDÜK, Z. \& KÜÇÜKOĞLU, S. (1999). Effects of age on the reciprocal peak torque ratios during knee muscle contractions in elite soccer players. Scandinavian Journal of Medicine \& Science in Sports, 9, 81-87.

HILL, A.V. (1938). The heat of shortening and the dynamic constants of muscle. Proceedings of the Royal Society of London, 126, 136-195.

HOFFMAN, J. (2006). Norms for Fitness, Performance, and Health. Edtion ed. Champaign: Human Kinetics.

IMPELLIZZERI, F.M., BIZZINI, M., RAMPINI, E., CEREDA, F. \& MAFFIULETTI, N.A. (2008). Reliability of isokinetic strength imbalance ratios measured using the Cybex NORM dynamometer. Clin Physiol Funct Imaging, 28, 914-918. 
KELLIS, S., GERODIMOS, V., KELLIS, E. \& MANOU, V. (2001). Bilateral isokinetic concentric and eccentric strength profiles of the knee extensor and flexors in young soccer players. Isokinetcis and Exercise Science, 9, 31-39.

KNAPIK, J.J., BAUMAN, C.L., JONES, J.M., HARRIS, J.M. \& VAUGHAN, L. (1991). Preseason strength and flexibility imbalances associated with athletic injuries in female collegiate athletes. American Journal of Sports Medicine, 5, 165-175.

LEHANCE, C., BINET, J., BURY, T. \& CROISIER, J.L. (2009). Muscular strength, functional performances and injury risk in Professional and junior elite soccer players. Scand J Med Sci Sports, 19, 243-251.

METAXAS, T.I., KOUTLIANOS, N., SENDELIDES, T. \& MANDROUKAS, A. (2009). Preseason physiological profile of soccer and basketball players in different divisions. Journal of strength and conditioning research, 23, 1704-1713.

LIN, Y.C., THOMPSON, A., KUNG, J.T., CHIEH, L.W., CHOU, S.W. \& LIN, J.C. (2010). Functional Isokinetic Strength Ratios in Baseball Players with injured elbows. Journal of Sport Rehabilitation, 19, 21-29.

MALÝ, T., ZAHÁLKA, F., \& MALÁ, L. (2010). Isokinetic strength, ipsilateral and bilateral ratio of peak muscle torque in knee flexors and extensors in elite young soccer players. Acta Kinesiologica, 4(2), 14-23. MALÝ, T., ZAHÁLKA, F., MALÁ, L., BUZEK, M., HRÁSKÝ, P., \& GRYC, T. (2011a). Vztah izokinetickej sily dolných končatín k rýchlostnym indikátorom bežeckej rýchlosti u mladých futbalistov. Česká kinantropologie, 15(3), 157-164.

MALŶ, T., ZAHÁLKA, F., \& MALÁ, L. (2011b). Differences between isokinetic strength characteristic of more and less successful professional soccer teams. Journal of Physical Education and Sport, 11(3), 306-312.

MORGAN, B.E. \& OBERLANDER, M.A. (2001). An examination of injuries in major league soccer. American Journal of Sports Medicine, 29, 426-430.

PARCELL, A.C., SAWYER, R. D. \& TRICOLI, V.A. (2002) Minimum rest period for strength recovery during a common isokinetic testing protocol. Med Sci Sports Exerc, 34, 1018-1022.

RAHNAMA, N., LEES, A. \& BAMBAECICHI, E. A. (2005). Comparison of muscle strength and flexibility between the preferred and non-preferred leg in English soccer players. Ergonomics, 48, 1568-1575. SVENSSON, M. \& DRUST, B. (2005). Testing soccer players. Journal of Sports Science, 23, 601-618.

WEIR, J.P. (2000) Youth and isokinetic testing. In. L.E. Brown (ed.) Isokinetics in Human Performance, (pp. 299-323), Champaign: Human Kinetic.

WILHITE, M.R., COHEN, E.R. \& WILHITE, S.C. (1992). Reliability of concentric and eccentric measurements of quadriceps perfomrance using the KIN-COM dynamometer: the effect of testing order for three different speeds. Journal of Orthopaedic and Sports Physical Therapy, 15, 175-182.

WIRTH, K. \& SCHMIDTBLEICHER, D. (2007). Periodisierung im Schnellkrafttraining. Leistungssport, $1,35-40$.

WONG, D.P. \& WONG, S.H.S., (2009). Physiological profile of Asian Elite youth soccer players. Journal of Strength and Conditioning Research, 23, 1383-1390.

WRIGLEY, T., \& STRAUSS, G. (2000). Strength Assessment by Isokinetic Dynamometry.

In. J. C. Gore (ed.), Physiological tests for elite athletes / Australian Sports Commission (pp. 155-198). Champaign: Human Kinetics. 